\title{
Chimaerism shown by cytogenetics and DNA polymorphism analysis
}

\author{
A J Green, D E Barton, P Jenks, J Pearson, J R W Yates
}

\begin{abstract}
A child with ambiguous genitalia, brought up phenotypically male, had a $46, X X / 46$, $X Y$ karyotype. At laparotomy, he had a left sided ovary and uterus, and a right sided scrotal testis. The $46, \mathrm{XX}$ line made up $50 \%$ of cells in the blood and $90 \%$ of cells in a skin biopsy. There were no cytogenetic polymorphisms. Analysis of lymphocyte DNA with seven polymorphic DNA markers showed him to be chimaeric, with four, three, and two parental alleles at different loci. He had one paternal and one maternal $X$ chromosome at the marker DXS1053. Based on our data, we would suggest that chimaerism arose as a result of postzygotic fusion of two embryos. We have shown by DNA polymorphisms the presence of autosomal chimaerism in a case of sex chromosome chimaerism, and indicated the usefulness of DNA polymorphisms in determining the origin of chimaerism.
\end{abstract}

\section{( $\mathcal{F}$ Med Genet 1994;31:816-817)}

Department of Clinical Genetics, Box 134, Addenbrooke's NHS Trust, Cambridge CB 2QQ UK

A J Green

J R W Yates

Molecular Genetics Laboratory,

Addenbrooke's NHS

Trust, Cambridge, UK

D E Barton

Cytogenetics

Laboratory,

Addenbrooke's NHS

Trust, Cambridge, UK

$P$ Jenks

Department of

Pathology, University of Cambridge, UK

A J Green

J R W Yates

Department of Cytogenetics, Norfolk \& Norwich Hospital, Norwich, UK $\mathrm{J}$ Pearson

Correspondence to Dr Green.

Received 31 May 1994 Revised version accepted fo publication 24 June 1994
An 18 month old child presented to the genetics clinic. He had been born at term with ambiguous genitalia, after an uneventful pregnancy, and it was decided to bring him up phenotypically male. He had a rudimentary phallus, with penoscrotal hypospadias and chordee (fig 1). His right gonad was palpable in the inguinal canal, but no left gonad was palpable. He had a linear area of pigmentation from umbilicus to genitalia. General physical examination was otherwise normal.

Peripheral blood karyotype at birth showed two cell lines of $46, \mathrm{XX} / 46, \mathrm{XY}$ at a ratio of approximately $50 \%$. Laparotomy performed at the age of 18 months showed a left ovary and fallopian tube, which were removed. The right gonad was biopsied and shown histologically to be normal testis. Karyotype of a skin biopsy showed a ratio of $83 \%$ in favour of the $46, \mathrm{XX}$ cell line.

Parental karyotypes were normal and no cytogenetic polymorphisms were seen in either parent. Analysis of peripheral leucocyte DNA from the child and his parents was performed using seven highly informative polymorphic DNA markers. Analysis of the microsatellite markers tyrosine hydroxylase (TH) and phenylalanine hydroxylase (PAH) showed that the

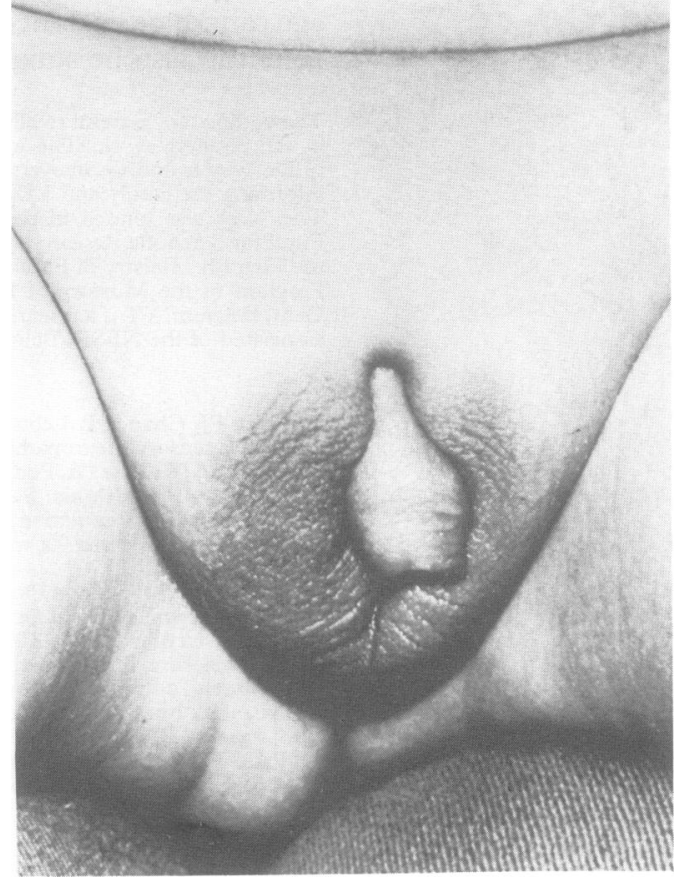

Figure 1 Photograph of the child's genitalia, showing a rudimentary phallus and an underdeveloped scrotum.

child had inherited both maternal alleles (see fig 2). As the father was homozygous for both markers, it was not possible to say whether the child had inherited one or two paternal alleles for these two loci. PCR analysis of the VNTR D4S95 showed that the child had inherited all four of his parents' alleles for this marker. The child was shown to have inherited only one of the two maternal alleles, but both paternal alleles at the actin related pseudogene microsatellite locus. Southern blot analysis of the VNTRs D16S85 and D16S309 showed that the child had inherited only one of each parental allele at this locus. Analysis of the microsatellite DXS1053 showed the presence of one of two maternal alleles and one paternal allele in the child.

Chimaerism can be partial or complete. Partial chimaerism can occur by placental exchange of bone marrow stem cells between dizygotic twins, by transfusions, or by organ grafting. Complete chimaerism involves all tissues and can occur in four ways. The first three of these (the fertilisation of an ovum and a polar body by two separate sperm and subsequent 


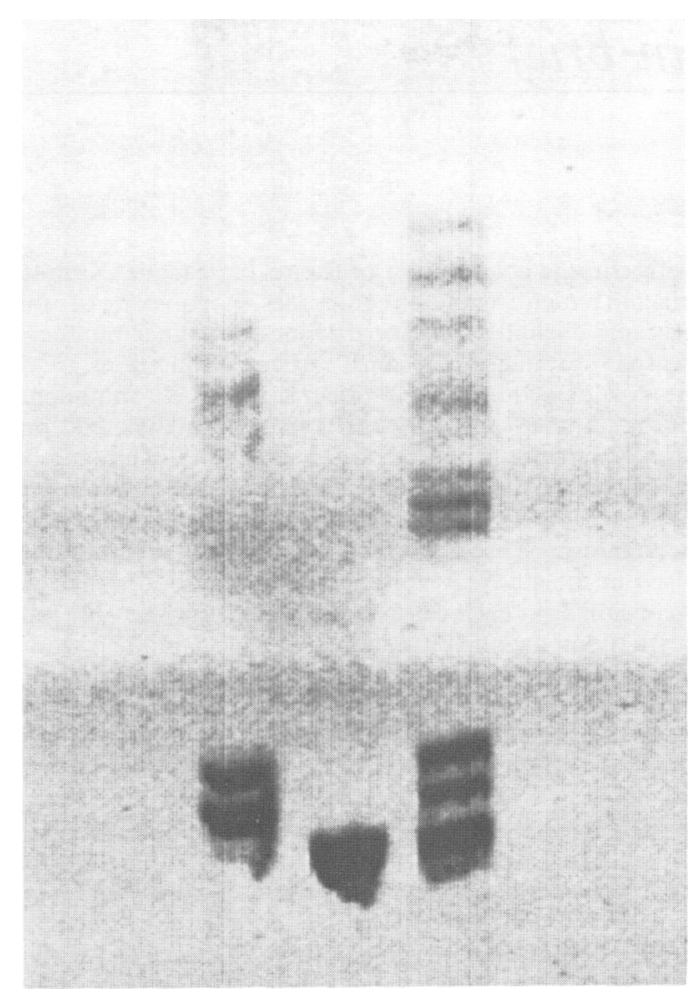

Figure 2 Photograph of PCR products of the marker PAH for mother (lane 1), father (lane 2), and child (lane 3), showing that the child has inherited both maternal alleles. Note the multiple duplex patterns in the child's PCR product, resulting from the presence of three alleles.

fusion of the zygotes, the fertilisation of a haploid ovum or polar body and subsequent fusion with a diploid oocyte, and the fusion of a diploid sperm with an embryo) are the products of a diploid gamete. The fourth mechanism is the postzygotic fusion of two distinct embryos.

The use of polymorphic markers to ascertain the method by which chimaerism has arisen is confounded by recombination between alleles at meiosis. The rates of recombination for such markers are low. Because of recombination, the presence of only one parental allele for several DNA markers in this patient cannot completely exclude chimaerism for that marker. Cytogenetic polymorphisms can help in this regard as they are more stable and have even lower rates of recombination. Cytogenetic polymorphisms were used by Dewald et al ${ }^{1}$ to suggest a mechanism for the development of the patient they described with sex chromosome chimaerism. However, such polymorphisms are far less common than microsatellite DNA markers. Unfortunately, this patient did not show any such cytogenetic polymorphisms.

On the assumption of a low marker recombination rate, we were able to postulate the mechanism of development of the chimaera. We could exclude the fusion of an embryo with a diploid oocyte as a cause of chimaerism by showing the presence of two paternal sex chromosomes, a paternal X chromosome using the marker DXS1053, and a paternal Y chromosome cytogenetically. The presence of one of two maternal $\mathrm{X}$ chromosomes would be consistent with any of the other three possible mechanisms of formation of a chimaera. On the assumption of a low recombination rate, a chimaera arising from the fertilisation of an ovum and polar body by two separate sperm would indicate the presence of either both maternal alleles at every marker, for a polar body from meiosis I, or only one maternal allele at every marker, for a polar body from meiosis II. As we have shown the presence of one of two maternal alleles for four DNA markers, and both maternal alleles for three DNA markers, this mechanism is unlikely. The fusion of a diploid sperm with an embryo would require the presence of both paternal alleles for every marker, in the absence of recombination. We have shown the presence in the chimaera of both paternal alleles for two DNA markers, and only one of two alleles for two other DNA markers. This makes a mechanism involving a diploid sperm unlikely. We are therefore left with the fourth mechanism of postzygotic fusion of two distinct embryos, one $\mathrm{XY}$ and the other XX, as the most likely cause of the chimaera. Our data from DNA marker analysis would be entirely consistent with this interpretation.

Chimaerism usually presents in the context of sex chromosome chimaerism with genital abnormalities, and has been shown by chimaerism for blood groups, protein polymorphisms, HLA serotypes, and cytogenetic polymorphisms. ${ }^{1-3}$ White cell chimaerism has been described after bone marrow or liver transplantation, detected by the use of protein and DNA polymorphisms. Red blood cell and occasionally white cell sex chimaerism has aiso been shown serologically in twins owing to exchange of bone marrow precursors in utero. In these cases, chimaerism has been confined to cells of bone marrow origin. ${ }^{4}$

The true extent of chimaerism, and the mechanisms by which this may occur, is difficult to estimate, as $\mathrm{XX} / \mathrm{XX}$ and $\mathrm{XY} / \mathrm{XY}$ chimaeras may not be ascertained, except by the incidental finding of more than two blood group or HLA protein polymorphisms. ${ }^{5}$ The use of DNA markers with very high levels of polymorphism can play a role in the detection of autosomal chimaerism and in analysing the mechanisms of chimaerism.

We have used polymorphic DNA markers to show autosomal chimaerism in the case of a child with sex chimaerism, and emphasise the usefulness of such markers in the detection of chimaerism. From our analysis, we would suggest that chimaerism in this case is the result of postzygotic fusion of two distinct embryos.

We would like to thank David Dow and Nicholas George for technical assistance.

1 Dewald G, Haymond MW, Spurbeck JL, Moore SB. Origin of chi46, XX/46, XY chimerism in a human true hermaphrodite. Science 1980;207:323-5

2 Takizawa $H$, Nakamura I, Hirasawa Y, Fujikura T, Ikawa K, Yamamoto T. Dispermic chimera associated with dysgerminoma. Exp Clin Immunogenet 1989;6:133-42.

3 Race RR, Sanger R. Blood groups in twins and chimeras. In: Race RR, Sanger R, eds. Blood groups in man. 6th ed. Oxford: Blackwell Scientific Publications, 1975:511-41.

4 Gonsoulin W, Copeland KL, Carpenter RJJ, Hughes MR, Elder FFB. Fetal blood sampling demonstrating chimerism in monozygotic twins discordant for sex and tissue karyotype (46,XY and 45,X). Prenat Diagn 1990;10:25-8.

5 Bromilow IM, Duguid JK. Blood group chimaerism: a possible further example. Med Lab Sci 1991;48:212-16. 